\title{
DSC Measurement of Frozen Water in Liquid Foods
}

\author{
Hitoshi Kumagai, Kozo Nakamura and Junichi Fujiwhara \\ Department of Agricultural Chemistry, The University of Tokyo, \\ Bunkyo-ku, Tokyo 113, Japan \\ Received December 11, 1984
}

\begin{abstract}
We investigated the state of water in frozen liquid foods, supposed to influence the performance of freeze-drying, by DSC. The amount of unfreezable water in milk was constant irrespective of the initial water content. As expected from the phase equilibrium, the water content of the non-ice part of CAS was constant among the samples with different initial water contents. The volume fraction of ice crystals, which should be known in the analysis of the freeze-drying rate, was significantly smaller at the low initial water content than the one usually estimated with the assumption that the water was all freezable.
\end{abstract}

Freeze-dried liquid foods such as tea and coffee have better taste and aroma retention, less chemical degradation, and faster dissolution rates than the products of alternative evaporative drying processes. On the other hand the slow drying rate and the expensive drying equipment are the drawbacks of freezedrying, and it is very important to predict the drying rate and the temperature distribution in the materials to design the best freeze-drying equipment and to select the conditions of drying. There has been much research reported on the freeze-drying of foods, but examination of the physical properties related to heat and mass transfer has been limited, and there are some ambiguities in the acquisition of data on the physical properties among the past valuable studies dealing with the drying rate.

The analysis of the freeze-drying rate has usually been based on the uniform retreating ice fron model (U.R.I.F model). The equations of heat and mass transfer are expressed below using this model when the material is heated by conduction through the frozen layer from the direction opposite to that of vapor permeation.

Equation of heat transfer:

$$
Q=\lambda \frac{T_{\mathrm{b}}-T_{\mathrm{s}}}{L-X}
$$

Equation of mass transfer:

$$
W=\frac{P_{\mathrm{s}}-P_{\mathrm{c}}}{(X / k)+R}
$$

Relationship between $Q$ and $W$ :

$$
Q=W H
$$

Vapor pressure at sublimating plane:

$$
P_{\mathrm{s}}=\mathrm{f}\left(T_{\mathrm{s}}\right)
$$

where $f$ is the function of vapor equilibrium.

The equation used in conversion of sample weight to thickness of dried part:

$$
X=\left(M_{\mathrm{o}}-M\right) /\left(\varepsilon \rho_{\mathrm{i}}\right)
$$

Equations $1 \sim 5$ can be used to simulate the course of freeze-drying if the physical properties and the rate constants are known. The void fraction, $\varepsilon$, is one of those constants appearing in Eq. 5. Toei et al. analyzed the rate of freeze-drying of ice with the assumption that water was all frozen. ${ }^{1)}$ In the work on the freeze-drying of foods, $\varepsilon$ has been also calculated as the volume fraction of initial water in the material with the assumption that the water was all frozen and dehydrated except the tightly bound water.

During the freezing of liquid foods the aqueous solution separates into ice crystals and a concentrated amorphous solution 
(CAS). Further cooling continues to concentrate the CAS with increases in the amount of ice. The solutions which readily form eutectics, for example, an aqueous solution of $\mathrm{KCl}$, stop forming ice sharply at the eutectic temperature. But such solutes as sugar and the mixtures of sugars contained in fruit juice, coffee, and other liquid foods cannot be nucleated, and formation of the solid eutectic mixture cannot occur. In cooling of liquid foods the viscosity of CAS becomes so large due to a cooperative effect of high concentration and low temperature that the formation of ice finally stops. ${ }^{1)}$

There usually appears an almost constant rate period in the initial stage of freeze-drying, and thereafter the drying rate decreased with some abruptness. This change of the dryingrate is supposed to be caused by a transition from the sublimation of ice to the evaporation of water unfrozen and bound in CAS. Therefore the volume fraction of ice crystals should be used as the void fraction, $\varepsilon$, in Eq. 5 if the dehydration is the sublimation of frozen water and not the evaporation of unfrozen and/or bound water in the constant rate period.

The phenomenon of the abrupt decrease in the drying rate is frequently named the collapse, and there have been several studies dealing with this penomenon. Ito measured the electric resistance and the collapse temperature of several pharmaceuticals. He showed, in case of the substances which make eutectic mixtures, collapse was due to the melting of the eutectic crystals. $^{4,5)}$ Bellows and King measured the DSC curve and the viscosity of frozen liquid foods, and showed that the collapse reflected a quantitative balance between surface tension and viscosity of the unfrozen concentrate. ${ }^{1)}$ When the freeze-drying collapses, the solute matrix loses its shape to result in such unfavorable qualities of the product as poor aroma retention, poor rehydration characteristics, and uneven dryness. ${ }^{1)}$ It is therefore important to know the reason for the decrease of the freeze-drying rate and to select the conditions keeping the drying rate as high as possible and the quality better.

In this study, the state of water in several liquid foods was measured by both DSC and electric resistance, and such properties as the amount of unfreezable water, the water content of the CAS, and the void fraction were calculated. These properties will be referred to in the following papers where the analysis of the drying rate using the modified U.R.I.F. model as well as the reason for a sudden decrease of the drying rate will be explained.

\section{MATERIALS AND METHODS}

Materials. The liquid used in DSC were milk, concentrated milk, concentrated coffee extract, and orange juice. Commercial milk and orange juice were used, and the coffee extract was obtained from Ajinomoto General Foods (AGF) Co. The concentrated milk was prepared by dissolving freeze-dried milk in warm water. The aqueous solution of $\mathrm{KCl}$ was also used as a solution making an eutectic mixture.

DSC measurement. Heat flux differential scanning calorimetry was done at the heating rate of $0.5^{\circ} \mathrm{C} / \mathrm{min}$ after cooling the sample down to $-55^{\circ} \mathrm{C}$ at approximately $1.4^{\circ} \mathrm{C} / \mathrm{min}$ using the low temperature type SSC 544 available from Seiko Denshi Kogyo Co., Ltd. The area bounded by the DSC curve, the corrected base line, derived in consideration of the time lag of heat response was numerically integrated and converted to the amount of liquid water with a constant value of heat of melting, $79.7 \mathrm{kcal} / \mathrm{kg}$. The total amount of water was calculated with the weight loss of the sample dried at $105^{\circ} \mathrm{C}$.

Measurement of electric resistance. The electric resistance during thawing of the sample was measured. One cubic centimeter of the sample in the Teflon vessel was frozen in liquid nitrogen until the temperature decreased to about $-80^{\circ} \mathrm{C}$. As the temperature of the sample left in the room thereafter was raised at the rate of $0.5 \sim$ $1.0^{\circ} \mathrm{C} / \mathrm{min}$, the electric resistance was measured with a circuit of a resistance bridge assembled on a glass plate, avoiding leakage of the current. It was confirmed from the theory of heat conduction that the temperature difference between the surface and the center of the sample was below $1^{\circ} \mathrm{C}$ at this rate of temperature increase. A direct current of $10 \mathrm{~V}$ was supplied to the sample when the resistance was measured continually. The principle of the measurement was almost the same as that of used by Hori et al. ${ }^{7)}$ 


\section{RESULTS AND DISCUSSION}

\section{DSC curves}

Figure 1 shows the typical DSC warming curves of several liquid foods and a $\mathrm{KCl}$ solution. As shown by the curves a1 and a 2 of Fig. 1, frozen milk begins to melt at about $-32^{\circ} \mathrm{C}$, and melts gradually as the temperature increases. Apparently the melting of milk continues above $0^{\circ} \mathrm{C}$. This is due to the time lag of the heat response. The curves $b$ and $c$ of Fig. 1 are those measured using coffee extract and orange juice, respectively. The coffee extract starts melting near $-40^{\circ} \mathrm{C}$, and a small peak is observed at about $-25^{\circ} \mathrm{C}$. The orange juice begins to melt at $39^{\circ} \mathrm{C}$, and the peak correspondingly to this melting temperature is relatively large. Two large peaks are observed on the DSC warming curve of $\mathrm{KCl}$ solution (curve d), and one of them appears at the temperature of eutectic melting.

\section{Amount of Unfreezable water}

Figure 2 shows the amount of unfreezable water in the frozen milk, which was calculated by integration of the DSC warming curve. The unfreezable water is temporarily defined in this study to be the water unfrozen until $-55^{\circ} \mathrm{C}$, while the unfrozen water means the water remaining unfrozen at each temperature above $-55^{\circ} \mathrm{C}$. The amount of unfreezable water is almost constant irrespective of the initial water content. Nagashima and Suzuki measured the amount of unfrozen water in the bean paste "miso" as well as several protein solutions by NMR. They observed that the amount of unfrozen water depended on the water content in the bean paste and the solution of gelatin or soy protein. ${ }^{3)}$ It is, however, noted that their result is different from the expectation derived from consideration of the phase equilibrium. The amount of unfreezable water was measured in the other liquid foods and the results are summarized in Table I.

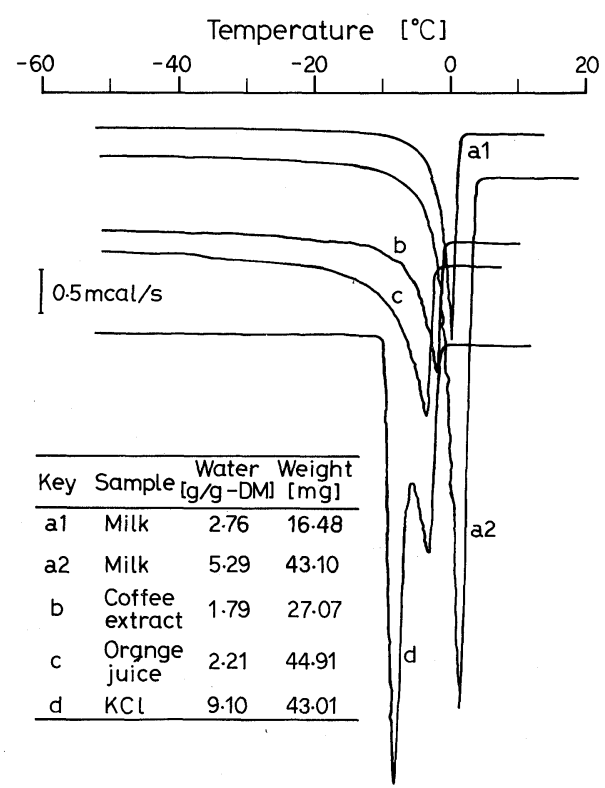

FIG. 1. DSC Thawing Curve of Liquid Foods and $\mathrm{KCl}$ Solution.

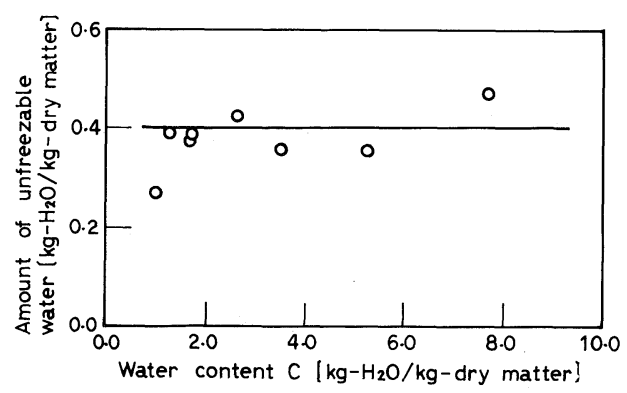

FIG. 2. Unfreezable Water of Milk Measured by DSC.

TABle I. Unfreezable Water of Liquid Foods MEASURED BY DSC

\begin{tabular}{llll}
\hline Sample solution & $\begin{array}{c}\text { Water } \\
\text { content } \\
{[\mathrm{kg} / \mathrm{kg}-\mathrm{DM}][\mathrm{kg} / \mathrm{kg}-\mathrm{DM}]}\end{array}$ & $\begin{array}{c}\text { Unfreezable } \\
\text { water }\end{array}$ & $\begin{array}{c}\text { Solidification } \\
\text { temperature* } \\
T_{\mathrm{e}}\left[{ }^{\circ} \mathrm{C}\right]\end{array}$ \\
\hline Coffee extract & 1.76 & $0.38 \sim 0.40$ & $-38 \sim-38$ \\
Orange juice & 2.21 & $0.53 \sim 0.60$ & -40 \\
Lactose & 6.28 & 0.48 & $-26 \sim-27$ \\
Milk & $1.0 \sim 8.0$ & 0.40 & -32.5
\end{tabular}

* The temperature measured was $-21.5^{\circ} \mathrm{C}$ for an aqueous solution of $\mathrm{NaCl}\left(9.0 \mathrm{~kg}-\mathrm{H}_{2} \mathrm{O} / \mathrm{kg}-\mathrm{DM}\right)$ and $-11^{\circ} \mathrm{C}$ for $\mathrm{KCl}$ an aqueous solution of $(9.1 \mathrm{~kg}$ $\mathrm{H}_{2} \mathrm{O} / \mathrm{kg}-\mathrm{DM}$ ), each of which corresponds to the eutectic temperature. 
3. Amount of frozen water and water content of $C A S$

Figure 3 shows the effects of temperature on the amount of frozen water divided by the total amount of freezable water and on the water content of the concentrated amorphous solution, CAS. The water content of CAS was considered to be the content of water unfrozen at the temperature concerned. The solution of $\mathrm{KCl}(9.10 \mathrm{~kg}$-water/kg-DM) melts sharply at its eutectic temperature, $-11^{\circ} \mathrm{C}$, and each of the liquid foods starts melting at a specific temperature. The orange juice melts at a lower temperature than the other liquid foods, and contains a larger amount of liquid water at each timperature. Figure 4 shows the effects of temperature on the fraction of frozen water and the water content of CAS formed in milk with different initial water contents. The fraction of frozen water increases as the initial water content becomes larger, while the water content of CAS does not increase due to the phase equilibrium of water between ice crystals and CAS.

\section{Volume fraction of ice}

The void fraction, $\varepsilon$, was calculated with the water content of CAS, $y$ using Eq. (6).

$$
\varepsilon=\frac{(C-y)}{(1+C)} \frac{\rho_{\mathrm{o}}}{\rho_{\mathrm{i}}}
$$

Figure 5 shows the effects of the initial water content on the void fraction of milk. The solid line is the void fraction calculated using the measured amount of unfrozen water, while the dashed line is the void fraction calculated with the value of $y$ assumed equal to zero. Usually the void fraction, $\varepsilon$, has been calculated to be the volume fraction of the initial water content in the material with the assumption that water was all frozen and dehydrated. ${ }^{8)}$ Actually the water is partly unfrozen, and dehydration in the constant rate period is supposed to proceed mainly by the sublimation of ice crystals. Therefore it was thought better to use the volume fraction of the ice crystals, as $\varepsilon$. According to Fig. 4 the water content of CAS, $y$ is almost constant, that is, $0.4 \mathrm{~kg} / \mathrm{kg}$-dry

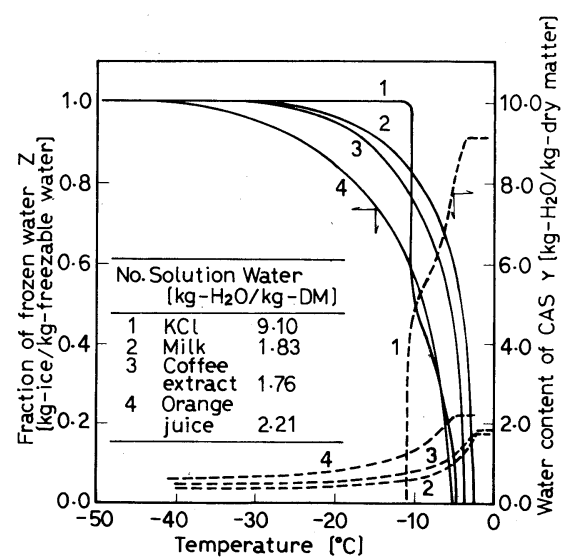

FIG. 3. State of Water in Several Frozen Solutions Measured by DSC.

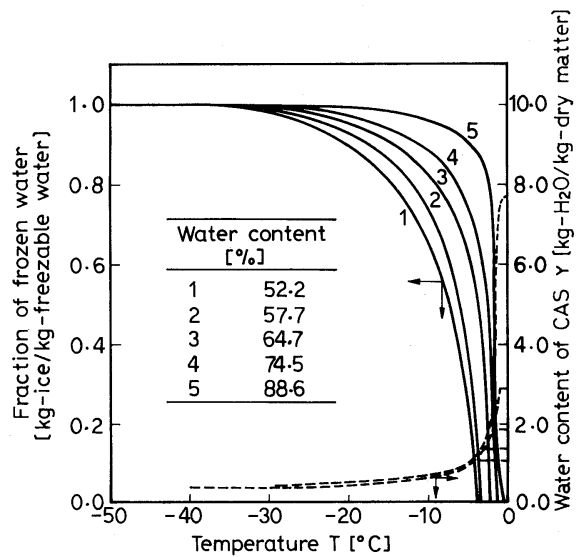

FIG. 4. State of Water in Frozen Milk Measured by DSC.

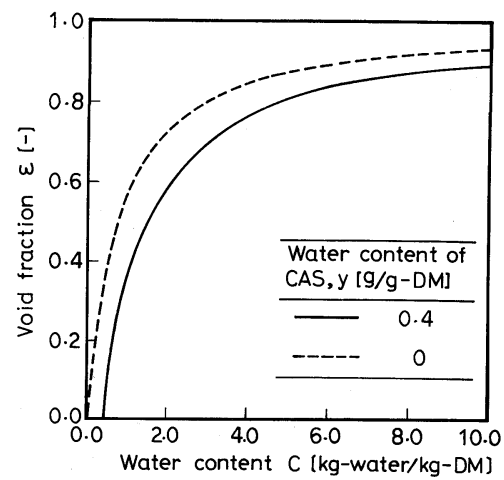

FIG. 5. Effects of Initial Water Content on Void Fraction of Frozen Milk.

matter below $-10^{\circ} \mathrm{C}$. The temperature of the frozen part was below $-15^{\circ} \mathrm{C}$ in almost all of the experiments of freeze-drying to be reported 


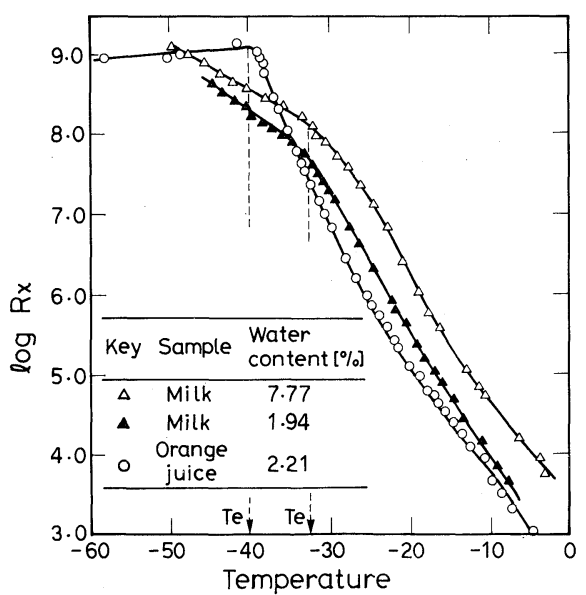

FIG. 6. Change of Electric Resistance with Temperature (Unit of $R_{\mathrm{x}}:[\Omega]$ ).

in the following paper. Therefore the value of $y, 0.4 \mathrm{~kg} / \mathrm{kg}$-dry matter, was used in the calculation of the solid line shown in Fig. 5. The drying rate will be analyzed with the void fraction of the solid line.

\section{Melting temperature}

Figure 6 shows the change of the electric resistance of milk and orange juice with increases of temperature. It is found that all the freezable water of milk freezes at $-32^{\circ} \mathrm{C}$, which is almost the same as the melting temperature measured by DSC. Figure 6 shows also that all the freezable water of orange juice freezes at $-40^{\circ} \mathrm{C}$. There is the temperature where the electric resistance changes with some sharpness, and it was assumed to be the solidfication temperature. The data are reported in Table I. The solidification temperature agreed with the melting point measured by the DSC method.

\section{NOMENCLATURE}

$A=$ Sectional area of sample

$\left[\mathrm{m}^{2}\right]$
$C=$ Initial water content

[kg-water/kg-dry matter]

$H=$ Latent heat of ice sublimation

$[\mathrm{J} / \mathrm{kg}]$

$k=$ Vapor permeability

$L=$ Thickness of sample

$M_{\mathrm{o}}=$ Initial sample weight

$[\mathrm{m}]$

$M=$ Sample weight

$[\mathrm{kg}]$

$P_{\mathrm{c}}=$ Vapor pressure in condenser

$[\mathrm{kg}]$

$P$ s $=$ Vapor pressure at sublimation plane

$Q=$ Heat flux $\quad\left[\mathrm{J} / \mathrm{m}^{2}\right]$

$R_{\mathrm{a}}=$ Resistance to vapor transferring from sample surface to condenser $\quad[\mathrm{m} / \mathrm{s}]$

$R_{\mathrm{x}}=$ Electric resistance $\quad[\Omega]$

$T_{\mathrm{b}}=$ Heater temperature $\quad\left[{ }^{\circ} \mathrm{C}\right]$

$T_{\mathrm{e}}=$ Solidification or eutectic temperature $\quad\left[{ }^{\circ} \mathrm{C}\right]$

$T_{\mathrm{s}}=$ Temperature of sublimation plane $\quad\left[{ }^{\circ} \mathrm{C}\right]$

$W=$ Drying rate $\quad\left[\mathrm{kg} /\left(\mathrm{m}^{2} \mathrm{~s}\right)\right]$

$X=$ Thickness of dried part

$y=$ Water content of CAS

$[\mathrm{m}]$

$z=$ Fraction of frozen water

[kg-water/kg-dry matter]

[kg-ice/kg-freezable water]

$\varepsilon=$ Void fraction $\quad[-]$

$\lambda=$ Thermal conductivity of frozen part $[\mathrm{W} /(\mathrm{mK})]$

$\rho_{\mathrm{i}}=$ Density of ice $\quad\left[\mathrm{kg} / \mathrm{m}^{3}\right]$

$\rho_{\mathrm{o}}=$ Density of frozen sample $\quad\left[\mathrm{kg} / \mathrm{m}^{3}\right]$

Acknowledgments. The authors would like to express their thanks to Assoc. Prof. T. Fujita and Dr. Y. Maeda for their help in DSC measurement.

\section{REFERENCES}

1) R. J. Bellows and C. J. King, AIChE Symp. Ser., 69, (132), 33 (1973).

2) Y. Guegov, Adv. Food Res., 27, 297 (1981).

3) N. Nagashima and E. Suzuki, Preprint of Symposium-Rheology and Phisical Properties for Food Processing, Tokyo 1982, p. 11.

4) K. Ito, Chem. Pharm. Bull., 18, 1509, 1519 (1970).

5) K. Ito, Chem. Pharm. Bull., 19, 1095 (1971).

6) R. Toei, M. Okazaki, and M. Asaeda, J. Chem. Eng. Japan, 8, 282 (1975).

7) T. Hori, M. Kako, and H. Hayashi, J. Fd. Sci., 47, 1254 (1982).

8) M. Karel, "Freeze-Drying and Advanced Food Technology," ed. by S. A. Goldblith, L. Rey, and W. W. Rothmayr, Academic Press, 1975, Chapter 14. 